Rev. Latinoam. Psicopat. Fund., São Paulo, v. 12, n. 4, p. 790-796, dezembro 2009

História da saúde no Rio de Janeiro: instituições e patrimônio arquitetônico (1808-1958) Pôrto, A.; Sanglard, G.; Fonseca, M.R.F. da; Costa, R.G.-R. (Org.) Rio de Janeiro: Fiocruz, 2008, 172p.

\title{
Sobre o arquivo da saúde: patrimônio, cultura e história no Rio de Janeiro
}

Organizada por Ângela Pôrto, Gisele Sanglard, Maria Rachel Fróes da Fonseca e Renato da Gama-Rosa Costa, com a colaboração de Cristina M. Oliveira Fonseca, todos pesquisadores da Casa de Oswaldo Cruz, a presente publicação abrange cinco artigos que integraram um projeto iniciado em 1994 com um levantamento de edifícios tombados ou em processo de tombamento e ligados à saúde. Feito por Benedito T. de Oliveira, Jayme Benchimol e Ângela Pôrto, a esse primeiro conjunto foram acrescidos outros prédios, identificados por Gama-Rosa e Sanglard, e instituições advindas do projeto Dicionário histórico-biográfico das ciências no Brasil (1832-1930), coordenado por Fróes da Fonseca.

Como resultado desse longo levantamento, surge esta publicação de textos analíticos acerca da história dessas edificações, acrescida ainda de um CD-Rom, com versões dos textos para inglês e espanhol e verbetes sobre todas as instituições pesquisadas. Ambos, livro e CD, acompanham uma bela iconografia dos monumentos, em um trabalho que busca aprofundar a tradição do patrimônio cultural da saúde no Rio de Janeiro.

A apresentação feita por Ângela Pôrto descreve cuidadosamente o percurso desse projeto, bem como seus produtos, livro e CD-Rom. Particu- 
larmente, o historiador, notadamente aquele que investiga a história das ciências da saúde no país, depara-se com um repertório de fontes bastante amplo e diversificado. Os verbetes, incluídos no CD em anexo, foram feitos com esforço analítico, compreendendo a interação das diversas instâncias da sociedade na produção dessas instituições. Trazem também a descrição arquitetônica dos edifícios e de suas modificações posteriores. Fornecem, pois, importante contribuição para a ampliação do patrimônio cultural da saúde no país.

O livro traz uma divisão cronológica marcada pelos diferentes textos, percorrendo a trajetória de um conjunto expressivo de instituições desde a chegada da família real (1808) até a mudança da capital (1960). As interpretações avaliam não apenas as características arquiteturais dos prédios escolhidos como objeto de análise, como também características conjunturais, promotoras de suas modificações ao longo do tempo. Desse modo, ao acompanhar longitudinalmente sua construção e utilização, os autores lançam mão de uma história do patrimônio que inclui o material e o imaterial, o que acaba por ultrapassá-las em sua materialidade.

Assim, os diversos textos explicitam, ao lado de referências arquitetônicas, referências científicas, assistenciais, técnicas, culturais e políticas de diferentes momentos históricos, deixando-nos entrever a construção de um arquivo "em cal e pedra" da saúde no país, marcado pela relação necessária entre prática, conhecimento e monumento. Desse ponto de vista deriva a principal qualidade dessa coletânea, sua unidade conceitual. E é partindo dessa unidade que é possível compreender os temas discutidos. Os autores apontam que

(...) é preciso que se leve em conta que a adoção de um determinado modelo institucional de prestação de serviços de saúde é em si uma opção política, traduz a escolha de um caminho, prioridades e definição de estratégias para alcançá-las. Além disso, o desenho institucional adotado pelo governo em um contexto político específico expressa também uma forma de relação na esfera pública entre as entidades governamentais e a população, que usufruirá desse bem coletivo. (p. 91)

Outra questão que atravessa todos os autores desse livro, de modo direto ou indireto, diz respeito à pertinência de se pensar a história das instituições integrada à natureza do conhecimento científico. Ao longo da coletânea, é possível perceber que se as instituições implantam práticas, essas influenciam e são influenciadas pelo conhecimento já produzido. A esse ponto de vista acrescenta-se também a compreensão de que os modelos institucionais devem ser analisados socialmente, orientação que traz também consequências na metodologia que agrupa esses autores.

Em consequência, o livro consegue conjugar estudos acerca de instituições específicas com questões histórico-culturais mais amplas, articulando àquelas 
questões as tensões sociais e político-ideológicas que competiram na organização de determinadas construções médico-hospitalares durante diferentes períodos históricos no Brasil. Isso significa dizer que os autores relacionam em seus artigos os diferentes projetos científicos e políticos identificados nas construções com propostas para a organização da sociedade, dando amplitude à análise histórica. É exatamente por isso que se torna possível também, a partir dessas mesmas instituições e de seus percursos, entrever as ideias de nação que surgiam nos diferentes períodos abrangidos pelo grupo de artigos.

Percorrer essas edificações implica necessariamente compreender também a história da saúde no país, em especial as características e transformações pelas quais a assistência hospitalar passou ao longo dos séculos XIX e XX. A arquitetura dessas construções reflete todo esse processo, já que revela o conhecimento médico do período e a relação adotada entre a saúde e a doença. Assim, os diferentes estilos e modelos arquitetônicos deixam transparecer concepções e formas de tratamento de doenças em sua época, sendo os prédios a materialização de políticas de saúde e de conhecimento científico. (p. 14)

O texto que introduz o livro, e que trata da "Memória, História e Patrimônio Cultural da Saúde", oferece ao leitor os conceitos de história, memória e patrimônio, a relação entre eles e as ações de preservar. Escrito por Gisele Sanglard e Renato da Gama-Rosa, é um metatexto, no sentido de que pretende orientar os temas a serem discutidos pelos autores seguintes.

Já o principal enfoque que introduz o texto "A saúde pública no Rio de Janeiro imperial”, de M. Rachel F. da Fonseca, são os debates científicos acerca das causas da saúde e da doença, bem como as alterações e rupturas deles decorrentes na passagem do período colonial para o imperial. A partir dessa introdução, que mostra, ao mesmo tempo, a organização da saúde após a chegada da família real e as mudanças administrativas, econômicas e culturais dela decorrentes, Rachel nos apresenta a seguir algumas das instituições derivadas dessas alterações fundamentais, como a Escola Anatômica, Cirúrgica e Médica do Rio de Janeiro (1808), o Instituto Vacínico do Império (1811), a casa de saúde que deu origem depois à Casa Dr. Eiras (1845), a Sociedade de Medicina do Rio de Janeiro (1829) e o Hospício Pedro II (1841). Entretanto, o peso de sua análise recai sobre a compreensão de causas, bem como os modos de organização e gestão de meios de combate às doenças na primeira metade do XIX e as adequações que se fizeram necessárias por causa do nível de insalubridade da cidade, demonstrando muito mais o processo gradual de institucionalização da higiene e da saúde no país.

Na parte seguinte do artigo, quando a autora discute a explosão de febre amarela entre 1849 e 1850 e sua importância para a regularização da saúde pú- 
blica na segunda metade do XIX, inicia-se um novo desfile de instituições, decorrentes dos novos e graves problemas sanitários que surgiam. Na busca de prevenir contra novas epidemias, o governo imperial criou em 1850 a Junta de Higiene Pública (que a partir de 1851 passou a se chamar de Junta Central de Higiene Pública), que atuava principalmente nos momentos de epidemia, seja de febre amarela, cólera-morbo ou varíola. Em 1876, após a Guerra do Paraguai, novas medidas foram tomadas. Paulatinamente, vários decretos foram regularizando as atribuições da Junta e as atividades foram se complexificando, ampliando-se por outros estados do império. Nesse contexto, foram também criados a Inspetoria de Saúde dos Portos, conselhos de saúde, comissões de saneamento etc. A questão da higiene e das epidemias, tão cara ao período, teve também reflexos na Faculdade de Medicina, que criou um instituto de higiene (1889) e começou a implementar laboratórios de análise e exame.

Após a República, novos decretos foram implementados. Em 1890 definiu-se um Conselho de Saúde Pública e a reorganização do serviço sanitário terrestre da República. No contexto republicano, "a saúde pública passou a domínio estatal em termos de organização e locais de atuação" (p. 45).

Assim, o texto termina tendo demonstrado que ao longo do século XIX, a preocupação com a salubridade da cidade cresceu enormemente entre administradores, médicos e estudiosos. Tal preocupação foi responsável por mudanças nas práticas da saúde que caracterizaram a medicina daquele período. Demonstra também como, paulatinamente, a Faculdade de Medicina passou a ser um lugar em que se concentraram os esforços para o encontro de soluções para as graves questões sanitárias do país, processo esse que foi sendo cada vez mais aliado ao uso do laboratório como espaço de legitimação da ciência, como demonstram os decretos de criação dos diferentes laboratórios no fim do século XIX.

Em período diferente, já na primeira república, Gisele Sanglard faz uma avaliação sobre a constituição da rede hospitalar no Distrito Federal. O foco principal do artigo é a análise do período entre 1906 e 1929, quando a autora percebe um evidente contraste frente ao que se daria após a década de 1930, tanto no que se refere às concepções de saúde e doença, como na esfera de ação do Estado. A partir de seu texto depreendemos que a assistência médica, até 1920, baseava-se principalmente na medicina liberal, que coexistia com a medicina filantrópica e com formas de sociedade de auxílio mútuo entre trabalhadores (Schraiber, 1993). O Estado promovia assistência somente aos militares e servidores públicos.

O principal é que, ao longo do texto, a autora chama atenção para os debates em torno da definição do que deveria ser a assistência pública. Na primeira parte, Gisele discute a transformação dos hospitais de lugar de caridade à espaço da terapêutica e de atendimento a população desde o Império, bem como o 
processo de medicalização dos hospitais, especialmente após a República. Na segunda parte, a autora explicita as características das organizações da assistência na cidade e sua compreensão do período histórico, com suas consequências para os debates acerca do Estado liberal e dos deveres do Estado frente à saúde da nação, ocorridos nos anos 1920. Esse período de transição, apontado no texto como indicativo de mudanças na política pública para a assistência, é marcado pela criação, em 1926, da Assistência Hospitalar, órgão da DNSP, que deveria gerir o Hospital São Francisco de Assis e o Hospital Nacional de Alienados (antigo Pedro II), além de fiscalizar os demais hospitais.

(...) a partir de 1918 não era mais o encontro da filantropia com as políticas públicas que estava sendo defendido e difundido pelos médicos, mas sim a criação e a construção de hospitais pelo poder público, pela União, e isso não apenas no Distrito Federal. Contudo, a transformação dos pleitos em realidade foi difícil. Se na década de 20 houve avanço na organização da assistência pública hospitalar é porque o recurso a filantropia se manteve. Por outro lado, foi nessa década que começaram as medidas para a criação da previdência social no Brasil e a saúde do trabalhador começou a se fazer presente. (p. 75)

Outra marca das mudanças institucionais e científicas que estavam ocorrendo em meio aos debates políticos do período é o projeto de construção dos primeiros hospitais com um novo modelo: em vez do modelo higiênico, de origem francesa, e que desde o império era a referência para a construção das edificações de saúde no país, surge o modelo pavilhonar alemão.

Esse período é, portanto, apontado como de fundamental transição, quer do conhecimento científico, quer da compreensão a respeito dos deveres do governo frente à educação e à saúde, bem como dos direitos do trabalhador. São essas as mudanças sinalizadas ao final de seu artigo, que termina com a passagem do Estado liberal da primeira república para o Estado de bem-estar social, proposto pelo governo Vargas.

$\mathrm{O}$ artigo seguinte, de Cristina M. Oliveira Fonseca, trata justamente das relações entre "Política e saúde: diretrizes nacionais e assistência médica no Distrito Federal no pós-1930". Segundo a autora, o período é marcado pela abertura de hospitais, o que decorre tanto da gestão do prefeito Pedro Ernesto como da gestão de Gustavo Capanema no Ministério da Educação e da Saúde (MES), demonstrando então como a construção e manutenção desses hospitais públicos se tornaria uma política de Estado ampla, tanto no nível municipal quanto federal. Assim, no que diz respeito à assistência, esse diálogo entre governo e saúde se estabeleceu também na dimensão organizacional da assistência,

(...) uma vez que é nesse período que normas e regras começaram a ser adotadas e impuseram diretrizes ao funcionamento do serviço público de saúde em todo 
país, com repercussões não apenas sobre o Distrito Federal, aliás, até então alvo prioritário dos investimentos e ações para a saúde. (p. 91)

Com a criação do MES e também do Ministério do Trabalho, Indústria e Comércio (MTIC), diferentes estruturas cada vez mais complexas foram surgindo para atender tanto ao trabalhador quanto aos que não possuíam trabalho formal, entregues agora à saúde pública, que, não por acaso, ficou atrelada à educação, para não apenas providenciar apoio à massa de "pré-cidadãos" (p. 92), mas também a fim de organizar no nível governamental uma prevenção capaz de transformá-los nos cidadãos do futuro. Tal viés ideológico está presente nas ações, na ampliação da rede hospitalar por todo o país, bem como no investimento para a formação de novos médicos e especialistas.

Desse modo, o campo da saúde modificou-se em função de uma política que compreendia que a atenção médica tinha de estar atenta às diferentes necessidades, segundo o grupo social a que se dirigia: os setores médios e a burguesia urbana, que se beneficiariam da prática médica privada e da seguridade social; e o proletariado urbano, dos seguros sociais de doença (Garcia, 1989).

A seguir, Gama-Rosa Costa traça a história da "arquitetura e saúde no Rio de Janeiro" ao longo do período analisado, demonstrando os diferentes modelos de saúde e de teorias a que tais edificações estão referidas. Assim, apresenta a arquitetura de prédios construídos ao longo do século XIX e início do XX, que buscam responder as questões da higiene através do modelo francês; trata da arquitetura pavilhonar, decorrente das descobertas de Pasteur e da microbiologia, e que encontram seu modelo na Alemanha; a partir da década de 1930, mostra a paulatina passagem desse para o sistema monobloco, de inspiração norte-americana, com suas racionalizações de circulação e trânsito de pessoal. Sua análise termina nos anos de 1950 e 1960, com a chegada do modelo do hospital tecnológico e triunfante, de arquitetura monobloco vertical, em constante diálogo com as novas modalidades hegemônicas das ciências médicas, mas agora também dominado pelos arquitetos e engenheiros.

Por fim, segue um glossário, além de uma lista com todas as construções selecionadas.

Ao fim da leitura desse livro, é possível perceber que as diversas formas de organização que assumiram as instituições médico-científicas e de assistência da saúde nos períodos analisados apontam para o fato de que as construções, na área da saúde, estiveram sempre atreladas ao social, cultural, científico, econômico e político que as cercavam. Esta conclusão, já debatida por outros estudiosos (c.f. Dantes, 2001, Latour, 1989), permite compreender o esforço conjunto em responder, através dos trabalhos que se consolidaram nesse livro, que há uma história das instituições brasileiras desde o período do império e que essas se 
organizaram a partir de tradições produzidas no país a partir de diversos matizes. Essas instituições cumpriram, assim, missões próprias do campo científico na sociedade, de acordo com o que se entendia na época como científico, como nos apontam Maria Rachel da Fonseca, Gisele Sanglard e Cristina Fonseca.

Além disso, há no conjunto da obra uma proposta implícita para se pensar nos modelos de assistência e instituições de saúde de hoje, desde que se considere como um projeto médico-arquitetônico corresponde a uma interpretação acerca do Homem, da saúde e da própria sociedade. Desse modo, os esforços deste trabalho de apresentar de forma ampla de onde partiram e para onde seguiram algumas das instituições importantes para a saúde no Brasil acabam por contribuir de maneira substantiva tanto para especialistas da história da saúde e das ciências, como para aqueles interessados na história do país.

\section{Referências}

Casa de Oswaldo Cruz/Fiocruz. Dicionário histórico-biográfico das ciências da saúde no Brasil (1832-1930). Disponível em: <http://www.dichistoriasaude.coc. fiocruz.br>. Acesso em: 20 abr. 2009.

Dantes, M. A. M. Espaços da ciência no Brasil: 1800-1930. Rio de Janeiro: Ed. Fiocruz, 2001.

Garcia, J.C. Pensamento social em saúde na América Latina. In: Nunes, E. D. (Org.). Pensamento social em saúde na América Latina. São Paulo: Cortez, 1989.

Latour, B. Qui combat? Les hommes ou les choses? Pasteur et Pochet: hétérogenàse de l'histoire des sciences. In: SERRES, M. Éleménts d'histoire des sciences. Paris: Bordas, 1989. p. 423-46.

Schraiber, L.B. O médico e seu trabalho. São Paulo: Hucitec, 1993.

\section{Cristiana FacchinetTI}

Psicanalista; doutora em teoria psicanalítica pela Universidade Federal do Rio de Janeiro - UFRJ (Rio de Janeiro, RJ, Brasil), com pós-doutoramento em História das Ciências e da Saúde pela Fundação Oswaldo Cruz - Fiocruz (Rio de Janeiro, RJ, Brasil); prof. do Programa de Pós-graduação em História das Ciências e da Saúde - PGHCS e pesquisadora do Departamento de Pesquisa - DEPES, ambos da Casa de Oswaldo Cruz/Fiocruz (Rio de Janeiro, RJ, Brasil). Av. Brasil, 4036/406 - Manguinhos 21040-361 Rio de Janeiro, RJ, Brasil 